\title{
Effectiveness of Ledipasvir/Sofosbuvir and Predictors of Treatment Failure in Members with Hepatitis C Genotype 1 Infection: A Retrospective Cohort Study in a Medicaid Population
}

\author{
George Kouris, PharmD; Tasmina Hydery, PharmD, MBA; Bonnie C. Greenwood, PharmD, BCPS; \\ Pavel Lavitas, PharmD, BCPS; Mylissa Price, MPH, RPh; Karen Clements, ScD; Caroline J. Alper, MD; \\ Kimberly Lenz, PharmD; and Paul L. Jeffrey, PharmD
}

\begin{abstract}
BACKGROUND: The primary goal of therapy for patients with chronic hepatitis $\mathrm{C}$ virus (HCV) infection is eradication of HCV ribonucleic acid, which is predicted by achievement of sustained virologic response at 12 weeks (SVR12). Ledipasvir/sofosbuvir was approved by the FDA in 2014 and 2015 as a once-daily regimen for the treatment of HCV genotype 1 and HCV genotypes 4,5 , and 6 , respectively. Although its efficacy has been demonstrated in randomized controlled trials, there is an unmet need for real-world effectiveness data and studies that assess the association of rates of SVR12 with specific clinical and demographic factors in the Medicaid population.
\end{abstract}

OBJECTIVES: To (a) evaluate the effectiveness of HCV genotype 1 treatment with ledipasvir/sofosbuvir as measured by the rate of SVR12 overall and within the subgroups of 8-, 12-, and 24-week regimens and (b) identify predictors of treatment failure in the Massachusetts Medicaid (MassHealth) population.

METHODS: This retrospective cohort study evaluated the rate of SVR12 among 796 MassHealth Primary Care Clinician and fee-for-service plan members who completed treatment with at least one 8-, 12-, or 24-week treatment with ledipasvir/sofosbuvir for HCV genotype 1 infection between 0ctober 10, 2014, and November 1, 2016. The following variables were evaluated to identify predictors of treatment failure: sex, history of treatment failure, cirrhosis, substance use disorder, human immunodeficiency virus coinfection, and concomitant use of interacting medications. The proportion of members who achieved SVR12 was calculated for the entire study population and stratified by treatment regimen. Chi-square tests were used to compare the proportion of members who achieved SVR12, stratified by clinical and demographic variables.

RESULTS: SVR12 was achieved in $95 \%(756 / 796)$ of members. High proportions of members who received 8 weeks of treatment or 12 weeks of treatment without concomitant ribavirin achieved SVR12 (96.0\% [285/297] and $95.7 \%$ [382/399], respectively). A slightly lower proportion of members who received 12 weeks of treatment with concomitant ribavirin or 24 weeks of treatment achieved SVR12 (89.9\% [62/69] and 87.1\% [27/31], respectively). The proportion of members who achieved SVR12 with each treatment regimen was consistent when stratified by clinical and demographic variables. None of the included variables were found to be associated with statistically significant differences in odds of treatment failure.

CONCLUSIONS: In the Medicaid population of 1 state, treatment of HCV genotype 1 infection with ledipasvir/sofosbuvir was associated with a high rate of SVR12. The outcomes of treatment of HCV genotype 1 infection with ledipasvir/sofosbuvir in the Medicaid population are comparable with outcomes observed in other patient populations.

J Manag Care Spec Pharm. 2018;24(7):591-97

Copyright $\odot 2018$, Academy of Managed Care Pharmacy. All rights reserved.

\section{What is already known about this subject}

Studies conducted in the Veterans Affairs system found that treatment with ledipasvir/sofosbuvir resulted in sustained virologic response at 12 weeks (SVR12) rates comparable with those seen in randomized controlled trials (89.4\%-98.5\%).

Prospective and retrospective observational studies using data from academic and community health centers, hepatitis $C$ virus (HCV) registries, and specialty pharmacies have also assessed real-world effectiveness of ledipasvir/sofosbuvir in HCV genotype 1 infection, with over $90 \%$ of patients achieving SVR12.

\section{What this study adds}

Similar to results from other data sources, high overall rates of SVR12 (95\%) following treatment of HCV genotype 1 infection with ledipasvir/sofosbuvir were further corroborated in the Medicaid population of 1 state.

Rates of SVR12 observed for individual treatment regimens were generally consistent with those observed in clinical trials and real-world effectiveness studies.

None of the clinical and demographic variables (sex, history of treatment failure, cirrhosis, substance use disorder, human immunodeficiency virus coinfection, and concomitant use of interacting medications) evaluated were associated with statistically significant differences in odds of treatment failure.

7 he Centers for Disease Control and Prevention estimates that 2.7-3.9 million people in the United States have chronic hepatitis $\mathrm{C}$ virus (HCV) infection. ${ }^{1}$ The primary goal of therapy for patients with chronic HCV infection is eradication of HCV ribonucleic acid (RNA), which is predicted by achievement of sustained virologic response at 12 weeks (SVR12). SVR12 is defined as confirmation of undetectable HCV RNA levels at 12 weeks after completion of therapy. Successful cure of HCV infection is associated with a significant reduction in the risk of hepatocellular carcinoma, liver transplantation, and all-cause mortality. In addition to health benefits for individual patients, curing HCV infection benefits public health by reducing the burden of disease and preventing 
further transmission. ${ }^{2}$ According to the American Association for the Study of Liver Diseases and Infectious Diseases Society of America and European Association for the Study of the Liver guidelines, all patients with chronic HCV infection should be considered for treatment with antiviral medications. ${ }^{2,3}$

Historically, the standard of care for treatment of chronic HCV infection has included a combination of peg-interferon and ribavirin, with or without boceprevir or telaprevir, which has resulted in suboptimal SVR12 rates, high rates of serious adverse events, longer treatment duration and higher intensity of monitoring. ${ }^{2}$ The availability of several new direct-acting antivirals (DAA) since 2013 has led to significantly improved treatment response rates. ${ }^{2}$ Harvoni (ledipasvir/sofosbuvir) was approved by the U.S. Food and Drug Administration in 2014 and 2015 as a once-daily tablet for the treatment of HCV genotype 1 and HCV genotypes 4, 5, and 6, respectively. ${ }^{4}$ There are at least 6 known genotypes, and in the United States, 74\% of chronic HCV infections are caused by genotype $1 .{ }^{1}$ In phase II and III trials, treatment of HCV genotype 1 infection with 8-week, 12-week, and 24-week regimens of ledipasvir/sofosbuvir, with or without concomitant ribavirin, consistently resulted in SVR12 in over 90\% of patients..$^{5-10}$

Two retrospective cohort studies conducted in the Veterans Affairs (VA) system found that treatment with ledipasvir/ sofosbuvir resulted in SVR12 rates comparable with those seen in randomized controlled trials (89.4\%-98.5\%). ${ }^{11,12}$ Several prospective and retrospective observational studies using data from academic and community health centers, HCV registries, and specialty pharmacies have also assessed real-world effectiveness of ledipasvir/sofosbuvir in HCV genotype 1 infection. Results are similar to those in the VA system, with over 90\% of patients achieving SVR12. ${ }^{13-18}$ Although the efficacy of ledipasvir/sofosbuvir has been demonstrated in randomized controlled trials and in a limited number of real-world effectiveness studies, there is an unmet need for real-world effectiveness data in the Medicaid population, in which the overall prevalence of $\mathrm{HCV}$ infection is approximately 7.5 times higher than it is in the commercially insured population. ${ }^{19}$ To the authors' knowledge, the only studies addressing use of ledipasvir/sofosbuvir in the Medicaid population have been evaluations of utilization and of factors that affect patient access to treatment. ${ }^{20,21}$

Furthermore, it is important to gather data regarding potential predictors of treatment failure with ledipasvir/sofosbuvir. Studies have assessed the association between the rate of SVR12 with ledipasvir/sofosbuvir in HCV genotype 1 infection and specific clinical and demographic factors, such as sex, history of treatment failure, presence of cirrhosis, concomitant use of medications that reduce the concentrations of ledipasvir or sofosbuvir, and human immunodeficiency virus (HIV) coinfection. ${ }^{5-10,12,14,22-25}$ However, none of these studies were performed in the Medicaid population, which may differ from other patient populations with regard to clinical and demographic characteristics. Also, while studies have been performed to assess outcomes of HCV treatment in patients with substance use disorder (SUD) before the availability of novel DAA therapies, there is minimal literature that has evaluated the effect of SUD on the rate of SVR12 with ledipasvir/sofosbuvir. ${ }^{26-31}$

The objectives of this study were to (a) evaluate the effectiveness of HCV genotype 1 treatment with ledipasvir/sofosbuvir as measured by the rate of SVR12 overall and within the subgroups of 8-, 12-, and 24-week regimens and (b) identify predictors of treatment failure in the Medicaid population of 1 state.

\section{Methods}

\section{Study Design and Data Source}

Massachusetts Medicaid (MassHealth) covers over 800,000 members in the Primary Care Clinician and fee-for-service (PCC/FFS) plans. The Clinical Pharmacy Services division of the University of Massachusetts Medical School (UMMS) is contracted by MassHealth to provide drug utilization management for both plans. MassHealth prior authorization criteria allow members access to treatment for HCV infection without restrictions based on liver fibrosis stage or SUD (Appendix A, available in online article). UMMS Clinical Pharmacy Services manages HCV medications through a comprehensive program known as the Hepatitis C Initiative. ${ }^{32}$ Data are prospectively collected in an internal database from prior authorization requests and prescriber outreach for programmatic purposes and includes treatment regimen, duration of therapy, date of treatment completion, viral load following treatment completion, and date of viral load measurement. Clinical and demographic data were obtained from this internal database. Information regarding drug interactions was obtained from pharmacy claims data. This study was approved by the UMMS Institutional Review Board before study initiation.

\section{Population Selection}

MassHealth members were included if they were aged 18 years or older, had a diagnosis of HCV genotype 1 infection, and completed at least one 8-, 12-, or 24-week course of treatment with ledipasvir/sofosbuvir between October 14, 2014, and November 1, 2016. In addition, they must have had continuous coverage through a MassHealth PCC/FFS plan for the duration of treatment and availability of posttreatment viral load data before November 1, 2016. Members were excluded if they had mixed HCV genotype or an HCV genotype other than genotype 1 and if they had an undetectable viral load drawn less than 12 weeks after completion of treatment.

\section{Outcomes}

The primary endpoint of this study was the proportion of members who achieved SVR12 after treatment with ledipasvir/ sofosbuvir, as confirmed by the prescriber's representative via 


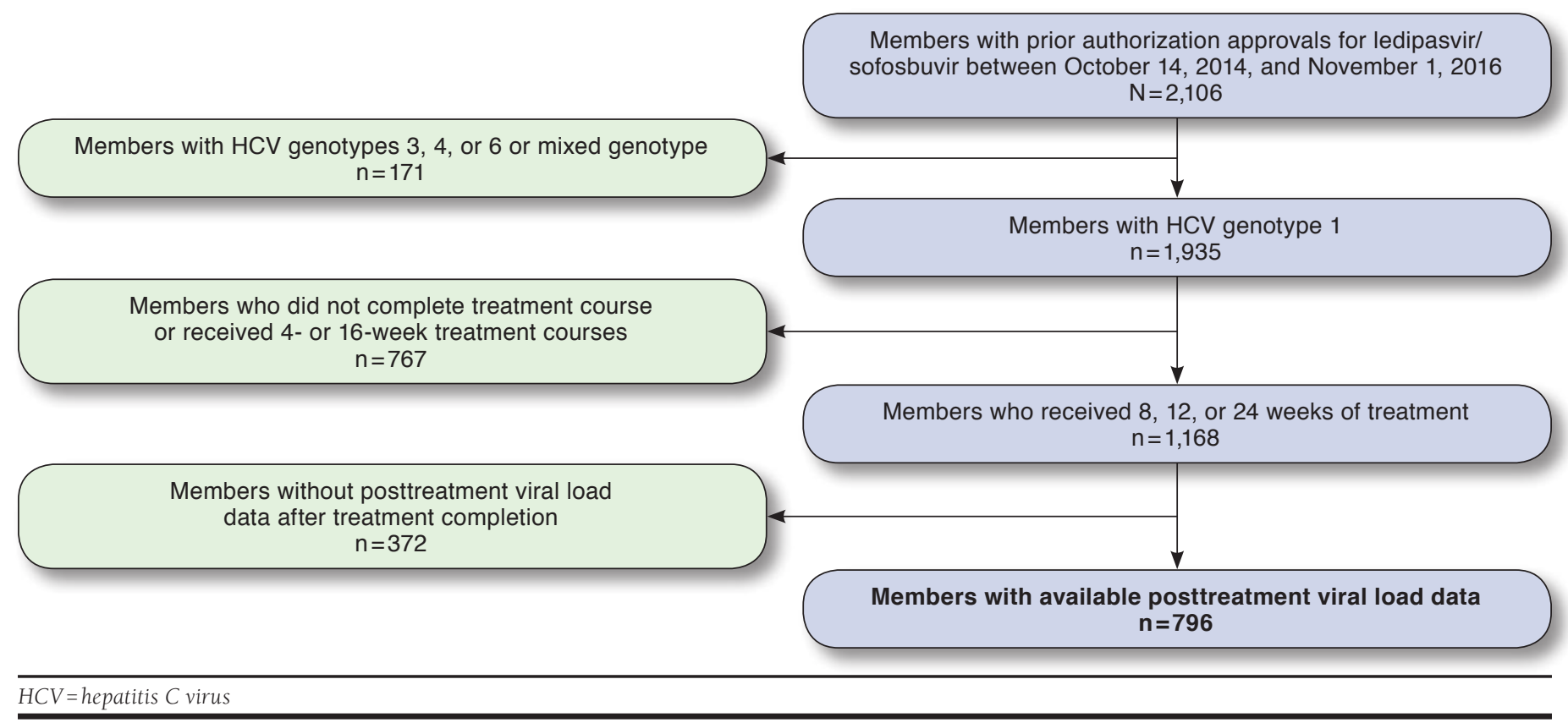

telephonic outreach. A detectable viral load at any point after completion of treatment was considered failure to achieve SVR12.

Data were also collected from prior authorization request forms to evaluate predictors of treatment failure. Clinical and demographic variables included age, sex, history of treatment failure, cirrhosis, baseline HCV RNA, SUD, HIV coinfection, and presence of a drug-drug interaction that may reduce the concentration of ledipasvir or sofosbuvir. Cirrhosis was defined as documentation of "cirrhosis" on a prior authorization request and/or a METAVIR score of "F4" or an Ishak score of "5" or "6." History of treatment failure was defined as the use of at least 1 treatment for HCV before treatment with ledipasvir/sofosbuvir. Any member who had at least 1 paid pharmacy claim for at least 1 drug that may be expected to reduce concentrations of ledipasvir or sofosbuvir during treatment with ledipasvir/ sofosbuvir was considered to have had a drug-drug interaction (Appendix B, available in online article).

\section{Statistical Analysis}

The proportion of members who achieved SVR12 was calculated for the entire study population and stratified by treatment regimen (8 weeks of ledipasvir/sofosbuvir, 12 weeks of ledipasvir/sofosbuvir with ribavirin, 12 weeks of ledipasvir/sofosbuvir without ribavirin, and 24 weeks of ledipasvir/sofosbuvir with or without ribavirin). Chi-square tests were used to compare the proportion of members who achieved SVR12 stratified by clinical and demographic variables. Logistic regressions were used to identify independent clinical and demographic predictors of treatment failure, adjusting for other model covariates. All analyses were performed using SAS version 9.3 (SAS Institute, Cary, NC). All associations were tested at a significance level of 0.05 .

\section{Results}

\section{Enrollment and Demographics}

Between October 10, 2014, and November 1, 2016, a total of 2,106 members had prior authorization requests approved for ledipasvir/sofosbuvir. After application of exclusion criteria, 796 members were included in this study. The majority of members were male (62.1\%) and treatment naive (79.0\%). Approximately one third of members (33.5\%) had cirrhosis. Few members had a documented HIV infection (17.8\%) or SUD (14.2\%), and less than 1 out of 10 had evidence of potential drug-drug interactions that may have reduced drug efficacy (7.0\%). The full member selection data is listed in Figure 1, and the baseline characteristics of members are described in Table 1 .

\section{Effectiveness Overall}

A large proportion of members achieved SVR12 (95.0\% [756/796]). Over $90.0 \%$ of members in each clinical and demographic subgroup also achieved SVR12. The full SVR12 results are described in Table 2. 


\begin{tabular}{|c|c|c|c|c|c|}
\hline Characteristic & $\begin{array}{c}\text { Ledipasvir/ } \\
\text { Sofosbuvir Total } \\
\text { for All Members } \\
\quad \mathrm{N}=796\end{array}$ & $\begin{array}{c}\text { Ledipasvir/ } \\
\text { Sofosbuvir } \\
\text { for } 8 \text { Weeks } \\
n=297\end{array}$ & $\begin{array}{c}\text { Ledipasvir/ } \\
\text { Sofosbuvir } \\
\text { for } 12 \text { Weeks } \\
\text { with Ribavirin } \\
\text { n=69 }\end{array}$ & $\begin{array}{c}\text { Ledipasvir/ } \\
\text { Sofosbuvir } \\
\text { for } 12 \text { Weeks } \\
\text { Without Ribavirin } \\
\mathbf{n}=399\end{array}$ & $\begin{array}{c}\text { Ledipasvir/ } \\
\text { Sofosbuvir } \\
\text { for } 24 \text { Weeks with } \\
\text { or Without Ribavirin } \\
\text { n=31 }\end{array}$ \\
\hline \multicolumn{6}{|l|}{ Sex, n (\%) } \\
\hline Male & $494 \quad(62.1)$ & $163(54.9)$ & $55 \quad(79.7)$ & $258(64.7)$ & $18 \quad(58.1)$ \\
\hline Female & $302(38.0)$ & $134(45.1)$ & $14 \quad(20.3)$ & $141 \quad(35.3)$ & $13 \quad(41.9)$ \\
\hline \multicolumn{6}{|l|}{ Age } \\
\hline Mean age, in years (SD) & $53.1 \quad(9.9)$ & $49.8 \quad(11.0)$ & $57.4 \quad(5.6)$ & $(8.9)$ & $57.4 \quad(7.7)$ \\
\hline \multicolumn{6}{|l|}{ Comorbidities, n (\%) } \\
\hline HIV & $142(17.8)$ & $0 \quad(0.0)$ & $\mathrm{b}$ & $128 \quad(32.1)$ & $\mathrm{b}$ \\
\hline SUD & $113(14.2)$ & $53 \quad(17.9)$ & $\mathrm{b}$ & $50 \quad(12.5)$ & $\mathrm{b}$ \\
\hline Cirrhosis & $267(33.5)$ & $0 \quad(0.0)$ & $56 \quad(81.2)$ & $181 \quad(45.4)$ & $30 \quad(96.7)$ \\
\hline \multicolumn{6}{|l|}{ Treatment history, n (\%) } \\
\hline Treatment naive & $629 \quad(79.0)$ & $297(100.0)$ & $19 \quad(27.5)$ & $311 \quad(77.9)$ & \multirow[b]{2}{*}{$\mathrm{b}$} \\
\hline Treatment experienced, total & $166 \quad(20.9)$ & $0 \quad(0.0)$ & $49 \quad(71.0)$ & $88 \quad(22.1)$ & \\
\hline \multicolumn{6}{|l|}{ Other, n (\%) } \\
\hline DDI & $56 \quad(7.0)$ & $13 \quad(4.4)$ & $\mathrm{b}$ & $27 \quad(6.8)$ & $\mathrm{b}$ \\
\hline
\end{tabular}

\section{Effectiveness by Regimen}

Large proportions of members who received 8 weeks of treatment or 12 weeks of treatment without concomitant ribavirin achieved SVR12 (96.0\% [285/297] and 95.7\% [382/399], respectively). Slightly smaller proportions of members who received 12 weeks of treatment with concomitant ribavirin or 24 weeks of treatment achieved SVR12 (89.9\% [62/69] and 87.1\% [27/31], respectively). The proportions of members who achieved SVR12 with each treatment regimen were fairly consistent when stratified by clinical and demographic variables. Of note, stratified data were not reported by member age and baseline HCV RNA to protect member privacy due to low numbers and lack of statistically significant differences among these characteristics.

None of the included variables were found to be associated with statistically significant differences in odds of treatment failure. The results of multivariate analyses of the odds of treatment failure with each of the clinical and demographic variables are listed in Table 3.

\section{Discussion}

In clinical trials evaluating the efficacy of ledipasvir/sofosbuvir for HCV genotype 1 infection, rates of SVR12 were high at over 90.0\%; similar rates of SVR12 have been observed in real-world effectiveness studies to date. With an overall SVR12 rate of $95.0 \%$ and rates ranging from $87.1 \%$ to $96.0 \%$ for individual treatment regimens, outcomes in this Medicaid population were comparable to outcomes observed in clinical trials and in other patient populations evaluated in real-world effectiveness studies.

While there was some variation in the rate of SVR12 between treatment regimens, comparative effectiveness of these regimens was not evaluated. Comparisons of treatment regimens may be confounded by differences in characteristics of the members treated. However, the rates of SVR12 observed for individual treatment regimens were generally consistent with those observed in clinical trials and real-world effectiveness studies.

A recent update to the clinical practice guideline includes a recommendation for 8 weeks of ledipasvir/sofosbuvir for the treatment of HCV genotype 1 in treatment-naive, noncirrhotic, nonblack patients without HIV coinfection and with a baseline viral load $<6$ million IU/mL. ${ }^{2,4}$ Members who received 8 weeks of ledipasvir/sofosbuvir in this study generally met these criteria, except that prior authorization requests were approved regardless of race. Given the high rate of SVR12 in this member population, the findings of this study provide additional support of the guideline recommendation. It is also worth noting that the rate of SVR12 was 93.2\% (41/44) in members with a METAVIR fibrosis score of F3 who received 8 weeks of treatment. This rate indicates that an 8 -week treatment regimen may be effective for noncirrhotic patients with advanced hepatic fibrosis.

A recent case-control analysis by Jansen et al. (2017) of predictors of treatment failure in 12 veteran patients treated with ledipasvir/sofosbuvir identified a pretreatment creatinine 


\begin{tabular}{|c|c|c|c|c|c|c|c|c|c|c|c|}
\hline Characteristic & \multicolumn{2}{|c|}{$\begin{array}{c}\text { Ledipasvir/Sofosbuvir } \\
\text { Total for All Members } \\
\mathrm{N}=796\end{array}$} & \multicolumn{2}{|c|}{$\begin{array}{c}\text { Ledipasvir/Sofosbuvir } \\
\text { for } 8 \text { Weeks } \\
n=297\end{array}$} & \multicolumn{3}{|c|}{$\begin{array}{c}\text { Ledipasvir/Sofosbuvir } \\
\text { for } 12 \text { Weeks with } \\
\text { Ribavirin } \\
n=69\end{array}$} & \multicolumn{2}{|c|}{$\begin{array}{c}\text { Ledipasvir/Sofosbuvir } \\
\text { for } 12 \text { Weeks } \\
\text { Without Ribavirin } \\
\mathbf{n}=399\end{array}$} & \multicolumn{2}{|c|}{$\begin{array}{c}\text { Ledipasvir/Sofosbuvir } \\
\text { for } 24 \text { Weeks with } \\
\text { or Without Ribavirin } \\
n=31\end{array}$} \\
\hline Total, n (\%) & \multicolumn{2}{|c|}{\begin{tabular}{|c|}
$756(95.0)$ \\
\end{tabular}} & \multicolumn{2}{|c|}{$285(96.0)$} & \multicolumn{3}{|c|}{\begin{tabular}{|c|}
$62(89.9)$ \\
\end{tabular}} & \multicolumn{2}{|c|}{$382(95.7)$} & \multicolumn{2}{|c|}{$27(87.1)$} \\
\hline \multicolumn{12}{|l|}{ Sex, n (\%) } \\
\hline Male & $469(94.9)$ & \multirow{2}{*}{$P=0.95$} & $155(95.1)$ & \multirow{2}{*}{$P=0.41$} & 49 & $(89.1)$ & \multirow{2}{*}{$P=0.68$} & $249(96.5)$ & \multirow{2}{*}{$P=0.31$} & $16(88.9)$ & \multirow{2}{*}{$P=0.73$} \\
\hline Female & $287(95.0)$ & & $130(97.0)$ & & 13 & $(92.9)$ & & $133(94.3)$ & & $11(84.6)$ & \\
\hline \multicolumn{12}{|l|}{ Comorbidities, n (\%) } \\
\hline HIV & $136(95.8)$ & $P=0.63$ & $0 \quad(\mathrm{~N} / \mathrm{A})$ & N/A & & $\mathrm{b}$ & $P=0.99$ & $124(96.9)$ & $P=0.44$ & $\mathrm{~b}$ & $P=0.45$ \\
\hline SUD & $107(94.7)$ & $P=0.89$ & $51(96.2)$ & $P=0.83$ & & $\mathrm{~b}$ & $P=0.49$ & $46(92.0)$ & $P=0.13$ & $\mathrm{~b}$ & $P=0.79$ \\
\hline Cirrhosis & $247(92.5)$ & $P=0.03$ & $0 \quad(\mathrm{~N} / \mathrm{A})$ & N/A & 49 & $(87.5)$ & $P=0.35$ & $172(95.0)$ & $P=0.53$ & $26(86.7)$ & $P=0.69$ \\
\hline \multicolumn{12}{|l|}{ Treatment history, $\mathrm{n}(\%)$} \\
\hline Treatment naive & $600(95.4)$ & \multirow{2}{*}{$P=0.30$} & $285(96.0)$ & \multirow{2}{*}{ N/A } & 17 & $(89.5)$ & \multirow{2}{*}{$P=0.95$} & $298(95.8)$ & \multirow{2}{*}{$P=0.88$} & $0 \quad(0.0)$ & \multirow{2}{*}{$P=0.02$} \\
\hline Treatment experienced, total & $156(93.4)$ & & 0 (N/A) & & 45 & $(90.0)$ & & $84(95.5)$ & & $27(93.1)$ & \\
\hline \multicolumn{12}{|l|}{ Other, $\mathbf{n}(\%)$} \\
\hline DDI & $51(91.1)$ & $P=0.17$ & $12(92.3)$ & $P=0.50$ & & $<11^{\mathrm{b}}$ & $P=0.57$ & $24(88.9)$ & $P=0.08$ & $<11^{\mathrm{b}}$ & $P=0.97$ \\
\hline
\end{tabular}

clearance $>90 \mathrm{~mL} / \mathrm{min}$ to be independently associated with treatment failure. ${ }^{33}$ Rapid viral response, previous treatment failure, histamine-2 antagonist therapy, ribavirin use, and cirrhosis were not predictive of treatment failure. ${ }^{33}$ In our study, the presence of cirrhosis was associated with the highest numerical difference in odds of treatment failure (odds ratio $=1.97 ; 95 \%$ confidence interval $=0.97-4.01$ ); however, similar to Jansen et al., we did not find previous treatment failure, drug-drug interactions, or cirrhosis to be associated with treatment failure. A large analysis, also among a veteran population, found that black and Hispanic patients were less likely to achieve SVR12 than white patients overall, and for patients with genotype 1 treated with 8 weeks of ledipasvir/sofosbuvir, black patients were less likely to achieve cure. ${ }^{34}$ Because reliable data for race/ethnicity were not available in our claims dataset, this variable warrants further investigation as a potential predictor of treatment failure in the Medicaid population.

\section{Limitations}

This study has a number of limitations. The observational design introduces the possibility of bias or confounding, which could diminish the validity of the results. Since data used in this study were derived entirely from the Medicaid program of 1 state, the results may not be generalizable to all other Medicaid populations.

This study excluded members who did not complete treatment or for whom posttreatment outcomes were not available in the internal database of the Hepatitis C Initiative. Lack of treatment completion documentation may represent a change in insurance and not necessarily discontinuation of treatment, while failure to obtain posttreatment outcomes from a prescriber's office may represent loss of a member to follow-up at the physician level. This study also excluded members who had an undetectable viral load less than 12 weeks after treatment completion, since this may not accurately represent treatment success or failure. These excluded members may have accounted for additional cure data.

Pharmacy claims data were only available for claims billed to a MassHealth PCC/FFS plan and were not available for claims billed to other payers or paid out of pocket by members. Therefore, members may have been taking other prescriptions and/or over-the-counter medications that may have interacted with ledipasvir or sofosbuvir, leading to additional drug interactions that were not captured in the pharmacy claims data. This situation may have resulted in underestimation of the number of drug interactions with ledipasvir/sofosbuvir. Data regarding history of failure of a previous HCV treatment were compiled from the internal database and did not discriminate between discontinuation of previous therapies because of adverse events, on-treatment virologic failure, or relapse after completion of a full treatment course.

Because treatment with ledipasvir/sofosbuvir is associated with a high rate of SVR12, the number of members who failed treatment in this study was small despite the relatively large sample size. The small number of members who failed treatment may have prevented any predictors of treatment failure from reaching statistical significance. 
Effectiveness of Ledipasvir/Sofosbuvir and Predictors of Treatment Failure in Members with Hepatitis C Genotype 1 Infection: A Retrospective Cohort Study in a Medicaid Population

TABLE 3 Odds of Treatment Failure by Clinical and Demographic Variables

\begin{tabular}{|c|c|c|c|c|c|}
\hline Characteristic & $\begin{array}{l}\text { Ledipasvir/ } \\
\text { Sofosbuvir Total } \\
\text { for All Members } \\
\qquad \mathrm{N}=796\end{array}$ & $\begin{array}{l}\text { Ledipasvir/ } \\
\text { Sofosbuvir } \\
\text { for } 8 \text { Weeks } \\
\quad \mathrm{n}=297\end{array}$ & $\begin{array}{c}\text { Ledipasvir/ } \\
\text { Sofosbuvir } \\
\text { for } 12 \text { Weeks } \\
\text { with Ribavirin } \\
n=69\end{array}$ & $\begin{array}{c}\text { Ledipasvir/ } \\
\text { Sofosbuvir } \\
\text { for } 12 \text { Weeks } \\
\text { Without Ribavirin } \\
\mathbf{n}=399\end{array}$ & $\begin{array}{c}\text { Ledipasvir/ } \\
\text { Sofosbuvir } \\
\text { for } 24 \text { Weeks with } \\
\text { or Without Ribavirin } \\
\mathbf{n}=31\end{array}$ \\
\hline \multicolumn{6}{|l|}{ Sex } \\
\hline Male & $(0.54-2.20)$ & $(0.16-1.94)$ & $(0.63-6.06)$ & $(0.07-6.05)$ & $(0.19-13.24)$ \\
\hline \multicolumn{6}{|l|}{ Comorbidities } \\
\hline HIV & $(0.35-2.13)$ & $\mathrm{N} / \mathrm{A}^{\mathrm{a}}$ & $(0.16-2.29)$ & $(0.08-6.97)$ & $\mathrm{N} / \mathrm{A}^{\mathrm{a}}$ \\
\hline SUD & $(0.52-3.31)$ & $0.85 \quad(0.18-4.09)$ & $(1.00-13.98)$ & N/A & N/A \\
\hline Cirrhosis & $(0.97-4.01)$ & N/A ${ }^{a}$ & $(0.31-3.69)$ & $\mathrm{N} / \mathrm{A}^{\mathrm{a}}$ & $\mathrm{N} / \mathrm{A}^{\mathrm{a}}$ \\
\hline \multicolumn{6}{|l|}{ Treatment history } \\
\hline Treatment experienced, total & $(0.46-2.32)$ & N/A ${ }^{a}$ & $(0.13-3.25)$ & $(0.17-5.68)$ & $\mathrm{N} / \mathrm{A}^{\mathrm{a}}$ \\
\hline \multicolumn{6}{|l|}{ Other } \\
\hline DDI & $(0.51-4.71)$ & $3.04 \quad(0.34-27.31)$ & $(0.43-10.63)$ & $\mathrm{N} / \mathrm{A}^{\mathrm{a}}$ & $\mathrm{N} / \mathrm{A}^{\mathrm{a}}$ \\
\hline \multicolumn{6}{|c|}{$\begin{array}{l}\text { Note: Values in this table are presented as } \mathrm{OR}(95 \% \mathrm{CI}) \text {. } \\
\text { a Odds ratio not calculable due to cell size of zero for at least } 1 \text { cell. } \\
C I=\text { confidence interval; DDI=drug-drug interaction based on claims history; HIV=human immunodeficiency virus; N/A=not applicable; OR=odds ratio; } \\
\text { SUD= substance use disorder. }\end{array}$} \\
\hline
\end{tabular}

Reliable data for race/ethnicity were not available at the time of this review and warrants further investigation as a potential predictor of treatment failure in the Medicaid population based on the results of past studies. ${ }^{11,34}$

\section{Conclusions}

$\overline{\text { Based on the results of this study, treatment of HCV genotype } 1}$ with ledipasvir/sofosbuvir is associated with a high rate of SVR12 in the Medicaid population of 1 state. These results indicate that the outcomes of treatment of HCV genotype 1 infection with ledipasvir/sofosbuvir in the Medicaid population are comparable with outcomes observed in other patient populations. They also demonstrate the potential societal benefits of expanding access to treatment of HCV infection.

\section{Authors}

GEORGE KOURIS, PharmD; TASMINA HYDERY, PharmD, MBA; BONNIE C. GREENWOOD, PharmD, BCPS; PAVEL LAVITAS, PharmD, BCPS; MYLISSA PRICE, MPH, RPh; and CAROLINE J. ALPER, MD, Clinical Pharmacy Services, University of Massachusetts Medical School, Shrewsbury. KAREN CLEMENTS, ScD; KIMBERLY LENZ, PharmD; and PAUL L. JEFFREY, PharmD, Center for Health Policy and Research, University of Massachusetts Medical School, Quincy.

AUTHOR CORRESPONDENCE: Tasmina Hydery, PharmD, MBA, Clinical Pharmacy Services, University of Massachusetts Medical School, 333 South St., Shrewsbury, MA 01545. Tel.: 774.455.3338; E-mail: Tasmina.Hydery@umassmed.edu.

\section{DISCLOSURES}

No outside funding supported this study. The authors have no financial disclosures.

A poster of this manuscript was presented at the Academy of Managed Care Pharmacy 2017 Annual Meeting, March 27-30, 2017, in Denver, Colorado.

\section{REFERENCES}

1. Centers for Disease Control and Prevention. Hepatitis C FAQS for health professionals. January 27, 2017. Available at: https://www.cdc.gov/hepatitis/ hcv/hcvfaq.htm. Accessed May 8, 2018.

2. American Association for the Study of Liver Diseases, Infectious Diseases Society of America. Testing, evaluation, and monitoring of hepatitis C. April 2017. Available at: http://www.hcvguidelines.org. Accessed May 17, 2018.

3. European Association for the Study of the Liver. EASL recommendations on treatment of hepatitis C 2016. J Hepatol. 2017;66(1):153-94.

4. Harvoni (ledipasvir and sofosbuvir) tablets, for oral use. Gilead Sciences. Revised November 2017. Available at: https://www.gilead.com/ /media/Files/ pdfs/medicines/liver-disease/harvoni/harvoni_pi.pdf. Accessed May 8, 2018.

5. Lawitz E, Poordad FF, Pang PS, et al. Sofosbuvir and ledipasvir fixed-dose combination with and without ribavirin in treatment-naive and previously treated patients with genotype 1 hepatitis $\mathrm{C}$ infection (LONESTAR): an open-label, randomized, phase 2 trial. Lancet. 2014;383(9916):515-23.

6. Bourliere M, Bronowicki JP, de Ledinghen V, et al. Ledipasvir-sofosbuvir with or without ribavirin to treat patients with HCV genotype 1 infection and cirrhosis non-responsive to previous protease-inhibitor therapy: a randomized, double-blind, phase 2 trial (SIRIUS). Lancet Infect Dis. 2015;15(4):397-404

7. Afdhal N, Zeuzem S, Kwo P, et al. Ledipasvir and sofosbuvir for untreated HCV genotype 1 infection. N Engl J Med. 2014;370(20):1889-98.

8. Afdhal N, Reddy KR, Nelson DR, et al. Ledipasvir and sofosbuvir for previously treated HCV genotype 1 infection. N Engl J Med. 2014;370(16):1483-93.

9. Kowdley KV, Gordon SC, Reddy RK, et al. Ledipasvir and sofosbuvir for 8 or 12 weeks for chronic HCV without cirrhosis. N Engl J Med. 2014;370(20):1879-88. 


\section{Effectiveness of Ledipasvir/Sofosbuvir and Predictors of Treatment Failure in Members with Hepatitis C Genotype 1 Infection: A Retrospective Cohort Study in a Medicaid Population}

10. Reddy KR, Bourliere M, Sulkowski M, et al. Ledipasvir and sofosbuvir in patients with genotype 1 hepatitis $C$ virus infection and compensated cirrhosis: an integrated safety and efficacy analysis. Hepatology. 2015;62(1):79-86.

11. Backus LI, Belperio PS, Shahoumian TA, et al. Real-world effectiveness of ledipasvir/sofosbuvir in 4,365 treatment-naïve, genotype 1 hepatitis C-infected patients. Hepatology. 2016;64(2):405-14.

12. Ioannou GN, Beste LA, Chang MF, et al. Effectiveness of sofosbuvir, ledipasvir/sofosbuvir, or paritaprevir/ritonavir/ombitasvir and dasabuvir regimens for treatment of patients with hepatitis $C$ in the Veterans Affairs national health care system. Gastroenterology. 2016;151(3):457-71.

13. Terrault NA, Zeuzem S, Di Bisceglie AM, et al. Effectiveness of ledipasvir-sofosbuvir combination in patients with hepatitis $C$ virus infection and factors associated of sustained virologic response. Gastroenterology. 2016;151(6):1131-40.

14. Younossi ZM, Park H, Gordon SC, et al. Real-world outcomes of ledipasvir/sofosbuvir in treatment-naive patients with hepatitis C. Am J Manag Care. 2016;22(6 Spec No.):SP205-11.

15. Lai JB, Witt MA, Pauly MP, et al. Eight- or 12-week treatment of hepatitis $C$ with ledipasvir/sofosbuvir: real-world experience in a large integrated health system. Drugs. 2017;77(3):313-18.

16. Vermehren J, Peiffer KH, Welsch C, et al. The efficacy and safety of direct acting antiviral treatment and clinical significance of drug-drug interactions in elderly patients with chronic hepatitis $C$ virus infection. Aliment Pharmacol Ther. 2016;44(8):856-65.

17. Tapper EB, Bacon BR, Curry MP, et al. Evaluation of proton pump inhibitor use on treatment outcomes with ledipasvir and sofosbuvir in a real-world cohort study. Hepatology. 2016; 64(6):1893-99.

18. Ingiliz P, Christensen S, Kimhofer T, et al. Sofosbuvir and ledipasvir for 8 weeks for the treatment of chronic hepatitis $C$ virus infection in HCV-monoinfected and HIV-HCV co-infected individuals: results from the German hepatitis C cohort (GECCO-01). Clin Infect Dis. 2016;63(10):1320-24.

19. Johnson RL, Blumen HE, Ferro C. The burden of hepatitis $C$ virus disease in commercial and managed Medicaid populations. Milliman. July 8, 2015. Available at: http://us.milliman.com/uploadedFiles/ insight/2015/milliman-hcv-burden.pdf. Accessed May 8, 2018.

20. Clements KM, Clark RE, Lavitas P, et al. Access to new medications for hepatitis $C$ for Medicaid members: a retrospective cohort study. J Manag Care Spec Pharm. 2016;22(6):714-22. Available at: https://www.jmcp.org/ doi/10.18553/jmcp.2016.22.6.714.

21. Do A, Mittal Y, Liapakis A, et al. Drug authorization for sofosbuvir/ ledipasvir (Harvoni) for chronic HCV infection in a real-world cohort: a new barrier in the HCV care cascade. PLoS One. 2015;10(8):e0135645.
22. Honer Zu Siederdissen C, Maasoumy B, Marra F, et al. Drug-drug interactions with all oral interferon-free antiviral agents in a real-world cohort. Clin Infect Dis. 2016;62(5):561-67.

23. Saab S, Park SH, Mizokami M, et al. Safety and efficacy of ledipasvir/ sofosbuvir for the treatment of genotype 1 hepatitis $C$ in subjects aged 65 years or older. Hepatology. 2016;63(4):1112-19.

24. Wyles D, Pockros P, Morelli G, et al. Ledipasvir-sofosbuvir plus ribavirin for patients with genotype 1 hepatitis $C$ virus previously treated in clinical trials of sofosbuvir regimens. Hepatology. 2015;61(6):1793-97.

25. Naggie S, Cooper C, Saag M, et al. Ledipasvir and sofosbuvir for HCV in patients coinfected with HIV-1. N Engl J Med. 2015;373(8):705-13.

26. Puoti M, Panzeri C, Rossotti R, Baiguera C. Efficacy of sofosbuvir-based therapies in HIV/HCV infected patients and persons who inject drugs. Dig Liver Dis. 2014:46(Suppl 5):S206-11.

27. Newman AI, Beckstead S, Beking D, et al. Treatment of chronic hepatitis $C$ infection among current and former injection drug users within a multidisciplinary treatment model at a community health centre. Can J Gastroenterol. 2013;27(4):217-23.

28. Melin P, Chousterman M, Fontanges T, et al. Effectiveness of chronic hepatitis $C$ treatment in drug users in routine clinical practice: results of a prospective cohort study. Eur J Gastroenterol Hepatol. 2010;22(9):1050-57.

29. Waizmann M, Ackermann G. High rates of sustained virological response in hepatitis $C$ virus-infected injection drug users receiving directly observed therapy with peginterferon alpha-2a (40KD) (PEGASYS) and oncedaily ribavirin. J Subst Abuse Treat. 2010;38(4):338-45.

30. Seidenberg A, Rosemann T, Senn O. Patients receiving opioid maintenance treatment in primary care: successful chronic hepatitis $C$ care in a real world setting. BMC Infect Dis. 2013;13:9.

31. Grebely J, Robaeys G, Bruggmann P, et al. Recommendations for the management of hepatitis $C$ virus infection among people who inject drugs. Int J Drug Policy. 2015;26(10):1028-38.

32. Lavitas P, Tesell M, Hydery T, et al. Overview of comprehensive hepatitis $C$ virus medication management in a state Medicaid program. J Manag Care Spec Pharm. 2016:22(10):1161-66. Available at: https://www.jmcp.org/ doi/10.18553/jmcp.2016.22.10.1161.

33. Jansen JW, Powderly GM, Linneman TW. Identification of predictors for treatment failure in hepatitis $C$ virus patients treated with ledipasvir and sofosbuvir. Ann Pharmacother. 2017;51(7):543-47.

34. Su F, Green PK, Berry K, et al. The association between race/ethnicity and the effectiveness of direct antiviral agents for hepatitis $C$ virus infection. Hepatology. 2017;65(2):426-38. 


\section{Effectiveness of Ledipasvir/Sofosbuvir and Predictors of Treatment Failure in Members with Hepatitis C Genotype 1 Infection: A Retrospective Cohort Study in a Medicaid Population}

\section{APPENDIX A MassHealth Prior Authorization Criteria for Ledipasvir/Sofosbuvir in HCV Genotype 1}

- Documentation of the following is required for treatment-naive members without cirrhosis:

$\circ$ diagnosis of chronic hepatitis $C$; and

$\circ$ hepatitis $C$ virus genotype $1,4,5$, or 6 ; and

$\circ$ member is aged $\geq 18$ years; and

- requested dose is $90 \mathrm{mg} / 400 \mathrm{mg}$ once daily; and

- medical records and results of diagnostic tests assessing hepatic fibrosis including tests supporting liver disease staging (e.g., APRI, Fibroscan, Fibrosure, FIB-4); and

- stage of liver disease is early stage (e.g., METAVIR score F0 to F2), or advanced stage (e.g., METAVIR score F3); and

- treatment will be discontinued if viral load is detectable at week 4 of treatment and has increased by greater than 10 -fold (>1 log 10 IU/mL) on repeat testing at week 6 (or thereafter); and

$\circ$ one of the following:

- for genotype 1 , member is aged $\geq 12$ and $<18$ years and requested duration is 12 weeks; or

- for genotype 1 , member is aged $\geq 18$ years and baseline viral load (within the last 6 months) $<6$ million IU/mL and requested duration is 8 weeks; or

- for genotype 1 , member is aged $\geq 18$ years and baseline viral load (within the last 6 months) $\geq 6$ million IU/mL and requested duration is 12 weeks; or

- for genotypes 4,5 , and 6 requested duration is 12 weeks.

- Documentation of the following is required for treatment-naive members with compensated cirrhosis or treatment-experienced members (failed treatment with peginterferon alfa and ribavirin, with or without protease inhibitor) without cirrhosis:

- diagnosis of chronic hepatitis $\mathrm{C}$; and

- hepatitis $C$ virus genotype $1,4,5$, or 6 ; and

- member is aged $\geq 18$ years; and

- requested dose is $90 \mathrm{mg} / 400 \mathrm{mg}$ once daily; and

- medical records and results of diagnostic tests assessing hepatic fibrosis including tests supporting liver disease staging (e.g., APRI, Fibroscan, Fibrosure, FIB-4); and

- stage of liver disease is early stage (e.g., METAVIR score F0 to F2), or advanced stage (e.g., METAVIR score F3 to F4, documentation of cirrhosis); and

$\circ$ requested duration is 12 weeks; and

- treatment will be discontinued if viral load is detectable at week 4 of treatment and has increased by greater than $10-$ fold $(>1 \log 10$ IU/mL) on repeat testing at week 6 (or thereafter).

- Documentation of the following is required for treatment-experienced members (failed treatment with peginterferon alfa and ribavirin, with or without protease inhibitor) with compensated cirrhosis:

- diagnosis of chronic hepatitis $\mathrm{C}$; and

- hepatitis $C$ virus genotype $1,4,5$, or 6 ; and

- member is aged $\geq 12$ years; and

- requested dose is $90 \mathrm{mg} / 400 \mathrm{mg}$ once daily; and

- medical records and results of diagnostic tests assessing hepatic fibrosis including tests supporting liver disease staging (e.g., APRI, Fibroscan, Fibrosure, FIB-4); and

- treatment will be discontinued if viral load is detectable at week 4 of treatment and has increased by greater than $10-$ fold $(>1 \log 10$ IU/mL) on repeat testing at week 6 (or thereafter); and

- one of the following:

- for genotype 1 , member is aged $\geq 12$ and $<18$ years and requested duration is 24 weeks; or

- for genotype 1 , member is aged $\geq 18$ years and requested duration is 12 weeks and requested regimen includes ribavirin; or

- for genotype 1 , member is aged $\geq 18$ years and requested duration is 24 weeks and prescriber provides clinical rationale for use of 24 -week treatment with ledipasvir/sofosbuvir instead of 12-week treatment with ledipasvir/sofosbuvir and ribavirin; or

- for genotype 4, 5, and 6, requested duration is 12 weeks; and

- for genotype 1 only, 1 of the following:

- documentation of initiation of treatment; or

- for continuation of treatment beyond 12 weeks, documentation of HCV RNA lab values at weeks 4 and 6 (if HCV RNA is detectable at week 5) supporting continued use.

APRI = aspartate aminotransferase to platelet ratio index; FIB-4 = Fibrosis-4 index; HCV=hepatitis $C$ virus; $R N A=$ ribonucleic acid. 
Effectiveness of Ledipasvir/Sofosbuvir and Predictors of Treatment Failure in Members with Hepatitis C Genotype 1 Infection: A Retrospective Cohort Study in a Medicaid Population

APPENDIX B Interacting Medications

- Carbamazepine

- Cimetidine $>800 \mathrm{mg} / \mathrm{day}$

- Dexlansoprazole $>30 \mathrm{mg} /$ day

- Esomeprazole $>20 \mathrm{mg} /$ day

- Famotidine $>80 \mathrm{mg} / \mathrm{day}$

- Lansoprazole $>30 \mathrm{mg} /$ day

- Nizatidine $>600 \mathrm{mg} / \mathrm{day}$

- Omeprazole > 20 mg/day

- Oxcarbazepine

- Pantoprazole $>40$ mg/day

- Phenobarbital

- Phenytoin

- Rabeprazole $>20 \mathrm{mg} /$ day

- Ranitidine $>600$ mg/day

- Rifabutin

- Rifampin

- Rifapentine

- Tipranavir/ritonavir 